\title{
Review in formulating the standard form of contract for Industrialized Building System (IBS) construction approach in Malaysia
}

\author{
Mohd Ashraf Mohd Fateh $^{1 \mathrm{a}}$, Mohammad Fadhil Mohammad $^{2}$ and Ani Saifuza Abd Shukor ${ }^{2}$ \\ ${ }^{1}$ Faculty Engineering and Technology Infrastructure, Infrastructure University Kuala Lumpur (IUKL) 40300 Kajang, Selangor, Malaysia \\ ${ }^{2}$ Faculty Architecture Planning and Surveying, Universiti Teknologi Mara (UiTM) 40450 Shah Alam, Selangor, Malaysia
}

\begin{abstract}
Industrialised Building System (IBS) is the common term used to represent the prefabrication concept in Malaysia. Based on previous research being done locally and internationally, it is certain that using IBS offers huge benefits in terms of cost, time, productivity and quality. The Malaysian construction industry has been urged to use innovative construction techniques. It is being highlighted under the present Construction Industry Transformation Programme 2016 - 2020 (CITP). These initiatives illustrate the Malaysia government's commitment in addressing the IBS agenda. Although some efforts have been taken to enhance the IBS adoption in Malaysia, various contract issues have emerged to become major concern amongst the IBS players that have led to delays, disputes, payment and cash flow issues in their projects. Formulating a dedicated standard form of contract for IBS construction approach is necessary to address the concerns. Therefore, the aim of the main research is to formulate the standard form of contract for IBS projects that will assist authorities and IBS industry players in mitigating the issues and challenges from the contractual perspectives. However, this paper will only present the literature reviews and findings from a preliminary survey conducted to establish pertinent contractual issues and challenges on the subject matter.
\end{abstract}

\section{INTRODUCTION}

The Malaysian construction industry has played a pivotal role in both its consumption of a wide range of goods and services, as well as through its provision of core infrastructure that has initiated growth and development throughout the country. Over the past five (5) years, Malaysia has experienced significant economic growth; having grown at a steady rate of $6 \%$ per annum as reported by the (Construction Industry Development Board (CIDB), 2015a). As reported by the (Department of Statistics, 2013) the local construction industry is an integral component of the Malaysian economy. It accounts for $3.7 \%$ of the total Gross Domestic Product (GDP). Moreover, the construction industry offers largescale positive spill over effects onto both the manufacturing and services sectors. Based on the report by the (CIDB), 2015c), the construction industry accounts for $15 \%$ of the total output of Malaysia's manufacturing sector. Beyond this, the construction industry plays a critical role in initiating and sustaining economic progress through the provision of infrastructure. The construction industry has been a real catalyst for the economic development enjoyed in recent years, as infrastructure development has been at the core of both the Economic Transformation Program (ETP) and the Tenth Malaysia Plan. By this figures, it is clear that the demand from the construction sector does a lot to propel the economy forward. In 2006, CIDB launched the Construction Industry Master Plan (CIMP) as a strategic roadmap to chart the path for the Malaysian construction industry towards becoming world-class. The success of CIMP underlined the necessity of having a blueprint for the construction industry. Through these achievements, CIDB is pleased to present Construction Industry Transformation Programme 2016 - 2020 (CITP). CITP'S vision is to transform the industry to become highly productive, sustainable and globally competitive, while raising the professional bar in the industry. 18 initiatives were introduced to support the CITP. One of the key initiatives in raising the productivity of the construction workforce is to drive higher technology adoption both in terms of the technology used in advanced construction methods (IBS). The Malaysian government is also committed not only in addressing the IBS agenda but also meeting its target and adopting innovations in the near future as reported by (Kamaruddin et al. 2013). (Shukor, Mohammad, \& Mahbub, 2011) also reported that the necessity of the Malaysian government to embark on rigorous initiatives and adopt the Industrialised Building System (IBS) as an innovative approach is a must to ensure Malaysia is globally competent, competitive and remain relevant. This suggestion is in line with P3 CITP's initiatives. Although the efforts mentioned above have been developed to push IBS adoption, the adoption rate is still low as reported by (CIDB), 2010). In order to

a mohd.ashraf.fateh@gmail.com 
accelerate the adoption of IBS, it needs more support from the stakeholders and construction players in the industry. The reason is that this new concept of construction uses a lot of innovative technology and the knowledge of construction is very crucial. From this scenario, it provokes this research to be conducted in line with the national construction industry agenda on P3 initiative, an acceleration adoption of modern construction method (IBS). This research will focus on the procurement and contract of implementation of IBS in the Malaysian construction industry. This research will give an insight of information and guidance to all the related stakeholders such as CIDB, Public Works Department (PWD), expert panels, academicians and related IBS players. The challenges in boosting the adoption of IBS projects would be looking at development of a standard form of contract for IBS projects, which may have a value-added impact on the success of IBS project implementation and delivery.

This paper is structured into two parts. Firstly, the review covers a broad range of literature, providing a concise overview on the general approach of IBS in the Malaysian construction industry, low adoption of IBS in Malaysia, lack of integration among IBS players, lack of standards for IBS projects and no standard form of contract for IBS projects. The second part discusses the findings and conclusions derived from evidence from the literature review and the preliminary study.

\section{LITERATURE REVIEW}

\subsection{Industrialised Building System (IBS) and the Malaysia Construction Industry}

In general, Industrialised Building System (IBS) is the term used to represent the prefabrication concept in Malaysia. The term was invented to shift from the typical paradigm of prefabricated systems. IBS is defined as a construction technique in which components are manufactured in a controlled environment (on or off site), transported, positioned and assembled into a structure with minimal additional site work. As reported by (Kamar et.al, 2009) some successful IBS implementations in the world are Sekisui Home (Japan), Living Solution (United Kingdom), Open House (Sweden) and Wenswonen (Netherlands).

It is the opposite of a conventional construction which is a common practice in Malaysia whereby most of the building components (beam, column, wall and etc) are cast in situ using timber framework while steel reinforcement is fabricated off-site. This method is labour intensive involving formwork fabrication, steel bending and concreting. It requires many wet trades on site such as skilled carpenters, plasterers and brick workers. The process can be hampered by quality issues, unfavourable site conditions, skilled labour shortages and bad weather conditions as reported by (CIDB), 2010). Based on previous research being done by local and international reseachers by (Construction Research Institute of
Malaysia (CREAM), 2011), (Sarja, 1998), (Gibb, 2001), (The UK government Department of Trade and Industry (DTI), 2004), (Nawi, Lee, Kamar, \& Hamid, 2011), ( Kamar et.al, 2009), (CIDB), 2015a), (Mohammad, 2013), (Shukor et al., 2011), (Musa, Mohammad, Yusof, \& Mahbub, 2015), (Halil, 2015) and (Kamaruddin et al. 2013 ) is certain that using IBS offers huge benefits in terms of cost and time certainty, attaining better construction quality and productivity, reducing risk related to occupational safety and health, alleviating issues on skilled workers and dependency on manual foreign labour and achieving the ultimate goal of reducing overall cost of construction. As reported by (CREAM), 2011) the Malaysian Construction Industry has been urged to use innovative construction technique and to shift from traditional practice to IBS construction. (CIDB), 2015a) reported that one key factor in raising the productivity of the construction workforce is to drive higher technology adoption both in terms of the technology used in advanced construction methods, e.g. IBS. In parallel with the national and construction industry agenda, CIDB is pleased to present the CITP. In this master plan, acceleration adoption of modern construction methods (especially using IBS) is one of the initiatives, initiatives P3. Therefore, this research is initiated to propel the acceleration adoption of modern constructions methods (IBS) parallel with the CITP.

\subsection{Low adoption in IBS}

Although IBS has been introduced for over 40 years, with well-documented benefits and strong support from the government, the pace of implementation and usage of IBS is still slow and below the government target as reported by (CIDB), 2015a) and (Nawi et al., 2011). Significant efforts have been put in place to push IBS adoption. IBS has been a strong agenda propounded by the YAB Prime Minister of Malaysia as evidenced by the government's commitment to deploy IBS for 34 schools in Sabah and Sarawak with further consideration to expand its usage. However, these efforts have yet to yield sufficient impact and the adoption rate is still low as reported by (CIDB), 2015b). The IBS roadmap $2011-$ 2015 by (CIDB), 2010) targeted an adoption rate of $70 \%$ for public sector projects and $50 \%$ for private sector projects; therefore the weighted average for IBS adoption should be at approximately 55\%. A survey conducted by CIDB in 2012 shows that Klang Valley by (CIDB), 2015a) -is seen to have to have the highest IBS adoption rate - has achieved a $46 \%$ IBS adoption rate, which is below target. In other regions in Malaysia, the gap is wider. In reality, IBS adoption is still relatively low and is still at its the growing stages as stated by (Halil, 2015) and (Shukor et al., 2011)

\subsection{Lack of integration among IBS players}

Further investigation by previous researchers (Kamar et.al, 2009), (Chung, 2006), (Haron et.al, 2005) and (Nawi et al., 2011) identified that one of the main barriers of IBS implementation in the Malaysian 
construction industry is related to poor integration and communication among stakeholders involved during the design and contract stage (Planning \& Regulation elements). As reported by (Hussein, 2007) the lack of integration among relevant players in the design and contract stage has resulted in a need for redesign and additional costs to be incurred if IBS is adopted. (Kamar et.al, 2009) reported that the pre-casters and contracting firm in Malaysia are only involved after the tender stage of the construction value chain. Whereby there is no integration during the design and contract stage. (CREAM), 2011) also stated that the integration of all parties in a project is the element in IBS that cannot be separated. The IBS players can improve better with proper planning, policies and management. Furthermore, (CREAM), 2011) stated, that the integration of various parties and supply chain to cooperate closely is also important. This requires very careful definition and management of interfaces between contractors and suppliers, and good communication channels. Furthermore, (Nawi et al., 2011) reported that improving procurement systems and supply chains is one of the key factors to achieving IBS success in the Malaysian construction industry. The report by (Halil, 2015) stated that one of the key reasons that the adoption of IBS in the Malaysian construction industry, has not been successfully implemented was due to lack of integration between the design and the construction stage. (Shukor et al., 2011) also stated that the fragmented scenario in the construction industry leaves the IBS supply chain players with noticeable difficulties in terms of competitiveness and efficiency. (CIDB), 2006), (Shukor et al., 2011) and (Mohammad et.al, 2014) also reported that the industry players were facing a difficult task to establish integration and cooperation between parties involved.

One of the critical success factors for IBS as reported by (Yusof et.al, 2014) is the management of supply chain and logistic activities, where a proper arrangement, in a manner that allows all parties to bind together and have the full control of the process. Therefore, integration is a very important aspect in construction. Without it, the project might fail. Due to this scenario, a development of a standard form of contract to act as a formal contract arrangement is a must to ensure all parties bind together, this it will promote and encourage integration among all.

\subsection{Lack of standards for IBS projects}

A research conducted by (Kamar et.al, 2009) stated that poor knowledge among the approving authorities has resulting misunderstanding and misinterpretation of IBS. It is also mentioned by (Chung \& Kadir, 2007) that most of the local authorities in Malaysia are unlikely to change local building regulations to suit IBS, as the amendment will consume a lot of time and cost. Even though the use of IBS assures valuable advantages in context of the local construction scenario, but new innovative management and procurement in IBS has still not been fully realised by the industry players and approving authorities as reported by (Shukor et al., 2011). Furthermore, (Shukor et al., 2011) also highlighted that poor knowledge and unfamiliarity with IBS concepts and processes as one of the factors in slow adoption of IBS in Malaysia. Therefore, the adoptions of IBS stay low as all the approving authorities are reluctant to migrate to use IBS because there are no a proper guidelines in term of contractual matters (standard form of contract). A standard form of contract is a very critical matter it will help all the approving authorities to decide and manage when handling an IBS project thus it might give them better understanding and ease the process of IBS adoption in Malaysia.

\subsection{No standard form of contract for IBS projects}

As reported by (CREAM), 2011) stated that contractors, manufacturers and suppliers agreed that factor that can contribute to the success of IBS in the Malaysia construction industry will be managing and coordinating IBS properly, not only from the construction perspective but also through the procurement and contract routine. For example, re-thinking the construction mechanism i.e. payment terms and deliveries as suggested by (CREAM), 2011). (Musa et al., 2015) also agreed that the payment and procurement mechanism needs to be reviewed to tailor to IBS activities which are reliable and for safer payment and procurement. The IBS players require safer and more reliable payment mechanism and contracts as reported by (CREAM), 2011). Change in construction methods and processes from conventional to IBS will affect the change in mode of payment and any related clauses in the contract. At this time, there is no security of payment designed for IBS projects and contractors need to deposit to manufacturers, which results in cash flows issues as reported by the (CREAM), 2011),(CIDB, 2015a) and (Shukor et al., 2011). (CIDB), $2015 \mathrm{~b}$ ) is proposing change in the public procurement approach. The existing procurement structures constraint contractors by requiring them to have high upfront financial capital to be able to procure IBS components from suppliers. (CIDB, 2015a) also reported the slow uptake of IBS is due to constraints or loopholes in regulations, specifications, requirements and standards that suits IBS environment and processes. Furthermore, a report by (Yusof et al., 2014) stated that processes and management and skill sets behind IBS differs from the traditional construction method. As reported by (Yusof et al., 2014), IBS requires partnership and close relationship with the suppliers and contractors from the early stages of construction. Most of the previous research by (CIDB, 2006, 2010; CREAM, 2011; Haron et.al, 2005; Hussein, 2007; Kamar et.al, 2009; Kamar et.al, 2009; Nawi et al., 2011), mainly touches on the IBS roadmap in Malaysia, the comparison between conventional and IBS construction, IBS challenges and benchmark reviews on the United Kingdom and Malaysia construction industry in IBS. On the other perspectives, previous research by (Halil, 2015; Kamaruddin et al., 2013; Mohammad et al., 2014; Mohammad, 2013; Musa et al., 2015; Shukor et al., 2011; Yusof et al., 2014) touches on challenges in the integrations of supply chain in IBS projects, economic perspectives on mechanisation 
and automation in IBS, the way forward for IBS in Malaysia, strategic partnering in IBS projects and key success factors in IBS projects. While, this research mainly focuses on contract and procurement aspect of IBS adoption. Due to this issue that have been brought up, all the industry players does not feel safe and secure as there are many contractual arrangement that is still vague. There are no proper guidelines to refer if things do not go as planned. Therefore, a dedicated standard form of contract that suits the IBS processes is necessary. By having it, all the clauses will be tailored to the IBS processes. For example clauses of deliverables, payment and materials on site will be covered. All the problems stated can be mitigated and addressed by developing a standard form of contract tailored to IBS projects. As to date, there is no dedicated standard form of contract for IBS projects in Malaysia. (CIDB, 2015a) reported that low adoption of IBS is due to a board definition of IBS and lack of standards. (CIDB, 2015a) also reported that there is room to potentially to establish a standard form of contract that reflects in a IBS environment and its processes. (Mohammad et al., 2014) also agreed that the procurement system plays an important role in the adoption of IBS. Furthermore, (Yusof et al., 2014) stated the introduction of different project procurement systems is needed to ensure more efficient and speedier project delivery systems and better project performance as one of the critical success factors in the adoption of IBS. A different procurement system will bring changes not only to the process and procedure of project delivery but also the aspects of management and organization. Findings from (Yusof et al., 2014) stated the establishment of integration among construction supply chains must take place to overcome the problems encountered.

\section{METHODOLGY}

Literature review and preliminary study with consenting respondents were used in data collection. By conducting the preliminary study to a variety of IBS players namely clients, contractors and manufacturers the seriousness of this issue and the significance of the research to the industry is genuine and valid were identified. However, since this research is still on going as this paper was being written, therefore the data presented in this paper is only the findings from the preliminary study.

Literature review was the first phase of the research with the secondary data derived from relevant books, journals articles, thesis and dissertations, conference proceedings and reports. The second phase involved the collection of primary data, wherein the information was collected through preliminary study. Table 1 illustrate the background of the preliminary study:

Table 1.Preliminary study background

\begin{tabular}{|l|l|}
\hline \multicolumn{1}{|c|}{ Description } & \multicolumn{1}{|c|}{ Remarks } \\
\hline Target respondents & $\begin{array}{l}\bullet \text { Clients } \\
\bullet \text { Contractors } \\
\bullet \text { Manufacturers }\end{array}$ \\
\hline Sampling frame & 10 respondents from CIDB's \\
\hline
\end{tabular}

\begin{tabular}{|l|l|}
\hline & records \\
\hline Duration & 2 month \\
\hline Methodology & $\begin{array}{l}\bullet \text { Structured interview } \\
\bullet \text { Discussion }\end{array}$ \\
\hline $\begin{array}{l}\text { Software of } \\
\text { analysis }\end{array}$ & Microsoft excel 2010 \\
\hline
\end{tabular}

\section{FINDINGS AND DISCUSSION}

$60 \%$ (6) of the respondents were clients, followed by $20 \%$ (2) were contractors and the last $20 \%$ (2) were manufacturers/distributors. Figure 1 summarizes on the respondent's sector. Most of the respondents that participated in the survey have vast experience in the construction industry and IBS projects. According to figure $2,50 \%$ (5) of the respondents have more than 10 years of experience in the construction, 30\% (3) with 6 to 10 years of experience in the construction industry followed by $20 \%$ (2) of respondents who have only 1 to 5 years of experience in the construction. A majority of the respondents have involved with more than 10 IBS projects. Figure 3 summarizes the respondent's involvement in IBS projects, which illustrates that $50 \%$ (5) respondents have been involved in more than 10 IBS projects as the highest percentage. The data collected represents that respondents are experienced both in the construction industry and involvement in IBS projects. Therefore, the data collected is considered to be reliable and good for the preliminary study.

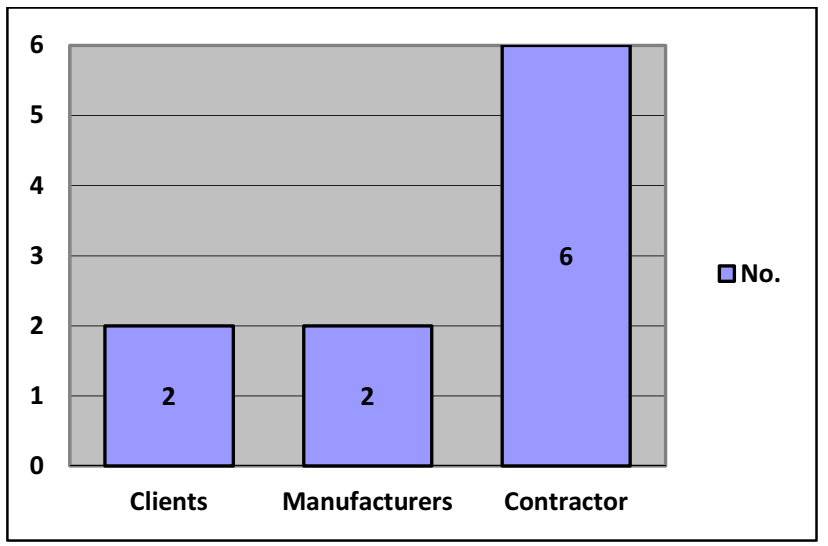

Figure 1.Respondent's sector

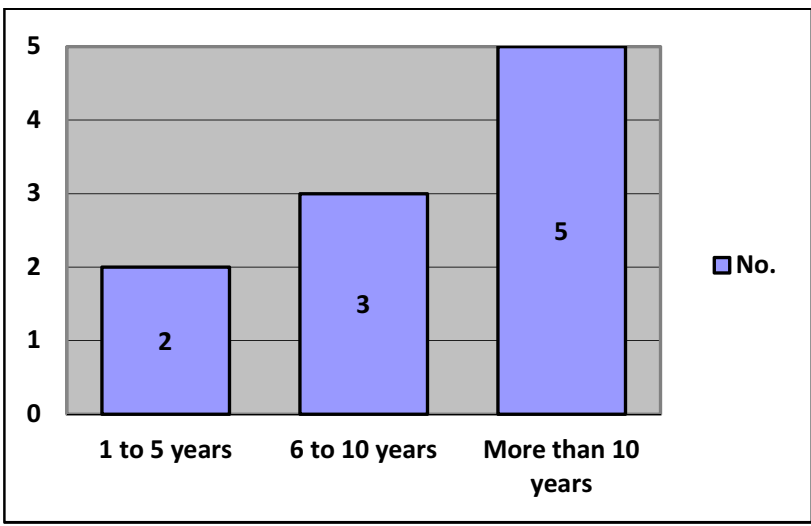

Figure 2.Respondent's experience in the industry 


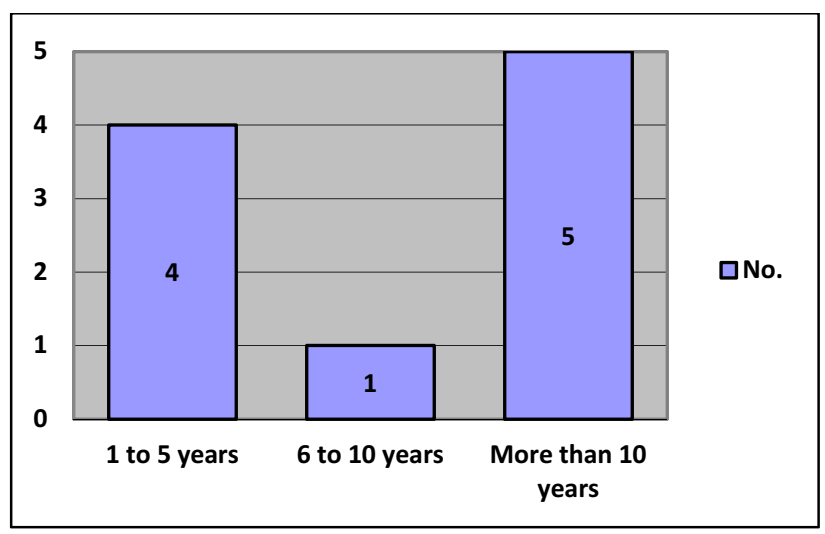

Figure 3.Respondent's involvement in IBS projects

Even though IBS has been in Malaysia for quite sometime, all the players are still facing some issues and challenges when adopting IBS, thus it contributes to the low adoption of IBS in Malaysia. 100\% (10) of the respondents admit that they have experienced any issues and challenges in adopting with IBS construction. Majority of the respondents admit that there is no standard form of contract which specifically tailors to the IBS construction approach, and activities is one of the major challenges that they are facing when implementing IBS construction approach. 90\% (9) of the respondents agree that there is no standard form of contract which tailored to IBS construction approach and activities. Table 2 summarizes the percentage of issues and challenges respondents have experienced in adopting the IBS construction approach. All respondents 100\% (10) agree it is a necessity to formulate a standard form of contract which specifically tailors to IBS construction approach.

Table 2. Issues and challenges the respondents experienced when adopting IBS construction

\begin{tabular}{|l|c|c|c|}
\hline Issues and challenges & Rank & No. & $\mathbf{( \% )}$ \\
\hline $\begin{array}{l}\text { No standard form of contract to } \\
\text { tailor IBS construction }\end{array}$ & 1 & 9 & 90 \\
\hline $\begin{array}{l}\text { Lack of knowledge from } \\
\text { industry players }\end{array}$ & 2 & 7 & 70 \\
\hline $\begin{array}{l}\text { Lack of integration among IBS } \\
\text { players }\end{array}$ & 3 & 6 & 60 \\
\hline $\begin{array}{l}\text { Lack of proper contract } \\
\text { arrangement }\end{array}$ & 3 & 6 & 60 \\
\hline Expensive & 5 & 4 & 40 \\
\hline Lack of standard for IBS projects & 5 & 4 & 40 \\
\hline Lack of machinery and supplier & 7 & 3 & 30 \\
\hline
\end{tabular}

Open ended question were asked to the respondents to comment and suggest on the current issues and challenges of IBS construction approach in Malaysia. The findings are summarize in table 3.
Table 3. Issues and challenges the respondents experienced when adopting IBS construction

\begin{tabular}{|c|c|}
\hline Theme & Comments / suggestion \\
\hline $\begin{array}{l}\text { Contractual } \\
\text { Clause }\end{array}$ & $\begin{array}{l}\text { 1. Payment security and offsite (start } \\
\text { from factory manufacturing to } \\
\text { delivering to site) } \\
\text { 2. The specification for IBS is quite } \\
\text { ambiguously spelled out in any } \\
\text { contract thus leads to confusion and } \\
\text { argument between the contractual } \\
\text { parties. There should be clauses in IBS } \\
\text { contracts so that implementation in the } \\
\text { industry would be smooth. } \\
\text { 3. Develop a standard form on contract } \\
\text { for IBS project to suit the decoupling } \\
\text { contract concept. } \\
\text { 4. The appointed consultants should be } \\
\text { well versed with the contractual } \\
\text { aspects with regards to IBS } \\
\text { construction to avoid unnecessary } \\
\text { delay when issuing instruction to } \\
\text { contractors. A special or dedicated } \\
\text { clause needs to be introduced for IBS } \\
\text { project. }\end{array}$ \\
\hline $\begin{array}{l}\text { Procurement } \\
\text { arrangement }\end{array}$ & $\begin{array}{l}\text { 1. Decoupling contract between client to } \\
\text { IBS manufacturer and contractors, may } \\
\text { results in: } \\
\text { - The reduction of price of } \\
\text { component } \rightarrow \text { direct between } \\
\text { clients to manufacturer } \\
\text { - Effective payment system } \\
\text { - Avoid project delay during } \\
\text { construction }\end{array}$ \\
\hline
\end{tabular}

2. Other elements, for example: integrated procurement \& BIM are equally important in the success of IBS delivery.

3. Most Malaysian contractors have little knowledge and experience in handling IBS system construction. The work is considered specialized and needs attention as to the process of construction from pre-planning up to the defect liability and maintenance period. Like the trades in construction such as piling, IBS should be introduced and trained as a specialist subcontractor. Likewise in the form of contract for IBS scope of work.

4. Dedicated procurement arrangements need to be introduced to cater for IBS project. It cannot rely solely on traditional/ conventional arrangement.

Integration $\quad 1$. It is important to understand that key \& supply success to delivery of IBS projects is chain the early integration of IBS during the planning \& design stage. 


\section{CONCLUSION}

From the preliminary study conducted, it shows that the industry is still facing issues and challenges when adopting IBS construction. The study also finds that formulating a standard form of contract for IBS construction approach is necessary to ensure smooth implementation as the activities are different from a normal construction approach. Previous research by (Shukor et al., 2011) and (Mohammad, 2013) have stated that, when there is a changes of technology or industrialisation in the industry, new and appropriate project procurement is needed. This is to ensure it can cater efficiently towards innovative activities. As every project is unique and dynamic in term of processes, resource allocation, risk exposure and responsibilities between all parties therefore the necessity of having a standard form of contract for IBS. For example, for a traditional design and build project, both approaches are different and each approach has their own standard form of contract which tailors to specific activities and construction processes. Therefore, it is crucial to conduct a research that is expected to give a guideline to the industry by developing a standard form of contract for IBS projects in Malaysia. The output of this research will give a good insight to the industry and help to accelerate the adoption of IBS construction in Malaysia as a whole.

\section{REFERENCES}

1. Chung, L. P. (2006). Implementation Strategy for Industrialized Building System. Johor.

2. Construction Industry Development Board (CIDB). (2006). Construction Industry Master Plan 2006-2015 (CIMP 2006-2015).

3. Construction Industry Development Board (CIDB). (2010). IBS Road Map, (72).

4. Construction Industry Development Board (CIDB). (2015a). Construction Industry Master Plan 2 (CIMP 2 2016-2020), (January 2015).

5. Construction Industry Development Board (CIDB). (2015b). Construction Industry Transformation Programme 2016 - 2020. Kuala Lumpur.

6. Construction Industry Development Board (CIDB). (2015c). Input-Output Table.

7. Construction Research Institute of Malaysia (CREAM). (2011). Proceedings of 1st IBS Roundtable Workshop. Vasa, 19. Retrieved from http://medcontent.metapress.com/index/A65RM03P4 874243N.pdf

8. Department of Statistics. (2013). Ecomonic Census of Contruction.

9. Gibb, A. G. F. (2001). Pre-assembly in Construction: $A$ review of recent and current industry and research initiatives on pre-assembly in construction In Construction Research \& Innovation Strategy Panel CRISP Consultancy Commission 00/19. London.

10. Halil, F. M. (2015). SUSTAINABLE VALUE TFIROUGH THE IMPLEMENTATION OF STRATEGIC PARTNERING IN
DTDUSTRIALISED BUILDING SYSTEM ( IBS ).

In International Symposium in Developing Economies: Commonalities Among Diversities (pp. $188-200)$.

11. Haron, N.A. Hassim, S. Kadir, M. R.A., Jaafar, M. S. (2005). Building Costing Comparison Between Conventional and Framework System. Journal of Technology, (43(B)).

12. Hussein, T. S. J. (2007). Industrialised Building System: The Challenges and Way Forward. Construction Industry Research Achievements International Conference, (Ciraic), 1-12.

13. Kamar, K. A. M., Alshawi, M. and Hamid, Z. A. (2009). BARRIERS TO INDUSTRIALIZED BUILDING SYSTEM ( IBS ): THE CASE OF MALAYSIA. In 9th International Postgraduate Research Conference (IPGRC). United Kingdom.

14. Kamaruddin, S., Mohammad, M., Mahbub, R., \& Yunus, R. (2013). Perception Towards Cost Implication of Mechanisation and Automation Approcah in IBS Projects in Malaysia. 29th Annual ARCOM Conference, (September 2013), 213-222.

15. Kamaruddin, S. S., Mohammad, M. F., \& Mahbub, R. (2013). Enhancing the Quality of Life by Adopting IBS: An Economic Perspective on Mechanisation and Automation. Procedia - Social and Behavioral Sciences, 101, 71-80. doi:10.1016/j.sbspro.2013.07.180

16. Kamarul Anuar Mohamad Kamar, Mustafa Alshawi, Zuhairi Abd. Hamid, Mohd Nasrun Mohd Nawi, Ahmad Tarmidzi Haron, M. R. A. (2009). Industrialised Building System (IBS): A Review of Experiences in Uk and Malaysian Construction Industry. 2nd Construction Industry Research Achievement International Conference (CIRAIC), 112.

17. Mohammad, M. F. (2013). Construction Environment: Adopting IBS Construction Approach Towards Achieving Sustainable Development. Procedia - Social and Behavioral Sciences, 85, 8-15. doi:10.1016/j.sbspro.2013.08.332

18. Mohammad, M. F., Saifuza, A., Shukor, A., Mahbub, R., \& Halil, F. M. (2014). Challenges in the Integration of Supply Chains in IBS Project Environment in Malaysia. Procedia - Social and Behavioral Sciences, 153, 44-54. doi:10.1016/j.sbspro.2014.10.039

19. Musa, M. F., Mohammad, M. F., Yusof, M. R., \& Mahbub, R. (2015). The Way Forward for Industrialised Building System (IBS) in Malaysia, (MAY). doi:10.1007/978-981-287-290-6

20. Nawi, M. N. M., Lee, A., Kamar, K. A. M., \& Hamid, Z. A. (2011). A critical literature review on the concept of team integration in industrialised building System (IBS) project. Malaysian Construction Research Journal, 9(2), 1-17.

21. Sarja, A. (1998). Open \& Industrialised Building, CIB (the International Council for Building Research Studies and Documentation).

22. Shukor, A. S. A., Mohammad, M. F., \& Mahbub, R. (2011). Supply Chain Integration Challenges in Project Procurement. Management and Innovation 
for a Sustainable Built Environment, (June).

23. The UK government Department of Trade and Industry (DTI). (2004). Modern methods of construction in Germany - playing the off-site rule In Global Watch Mission Report. United Kingdom.

24. Yusof, M. R., Nawawi, A. H., Mohammad, M. F., \& Musa, M. F. (2014). Key Success Factors in IBS Project Management Key Success Factors in IBS Project Management, (APRIL). 